\author{
Yi-Hsi Wang \\ An-Shen Lin \\ Tung-Ying Chao \\ Sheng-Nan Lu \\ Jien-Wei Liu \\ Shun-Sheng Chen \\ Meng-Chih Lin
}

\section{A cluster of patients with severe acute respiratory syndrome in a chest ward in southern Taiwan}

Received: 7 November 2003

Accepted: 29 March 2004

Published online: 23 April 2004

(C) Springer-Verlag 2004

Y.-H. Wang · A.-S. Lin - T.-Y. Chao •

M.-C. Lin (

Division of Pulmonary

and Critical Care Medicine,

Department of Medicine,

Chang Gung Memorial Hospital,

Kaohsiung, Chang Gung University,

123 Ta Pei Road, Niao Sung Hsiang,

Kaohsiung Hsien, 833 Taipei, Taiwan

e-mail: mengchih@adm.cgmh.org.tw

Tel.: +886-7-7317123

Fax: +886-7-7318762

S.-N. Lu

Division of Gastroenterology,

Department of Medicine,

Chang Gung Memorial Hospital,

Kaohsiung, Chang Gung University,

123 Ta Pei Road, Niao Sung Hsiang,

Kaohsiung Hsien, 833 Taipei, Taiwan

J.-W. Liu

Division of Infectious Diseases,

Department of Medicine,

Chang Gung Memorial Hospital,

Kaohsiung, Chang Gung University,

123 Ta Pei Road, Niao Sung Hsiang,

Kaohsiung Hsien, 833 Taipei, Taiwan

S.-S. Chen

Department of Neurology,

Chang Gung Memorial Hospital,

Kaohsiung, Chang Gung University,

123 Ta Pei Road, Niao Sung Hsiang,

Kaohsiung Hsien, 833 Taipei, Taiwan

\begin{abstract}
Objective: Severe acute respiratory syndrome (SARS) is an emerging and easily clustering infectious disease. We describe an outbreak of SARS in a chest ward of a medical center in southern Taiwan and seek to identify the risk factors of those SARS patients who required mechanical ventilation. We focus on previous health patients. Design: This retrospective case series was collected during the SARS outbreak. Degrees of severity were established, based on whether intubation and mechanical ventilation was necessary. Setting: A 2500-bed medical center in southern Taiwan. Patients: Forty-four patients exhibited symptoms that met the modified World Health Organization (WHO) definition of SARS. These included of three subgroups: healthcare workers $(n=16)$, relatives $(n=14)$, and patients already admitted for other ailments $(n=14)$. Of these, 20 eventually required mechanical ventilation. Measurements and results: Laboratory analyses showed statistically significant differences between intubated and nonintubated patients in white blood cell count, neutrophil percentage, and C-reactive protein level as well as in age and underlying malignancy. Risk factors for SARS
\end{abstract}

patients who had been healthy prior to their illness included old age, high peak fever grade, increased neutrophil count, increased neutrophil percentage, and close or prolonged contact with a SARS patient. Conclusions: Old age, high white blood cell counts, high peak grade fever, and close or prolonged contact with a SARS patient increase the risk of intubation in previous healthy SARS patients.

Keywords SARS · Southern Taiwan - Intubation · Old age . Health-care worker

\section{Introduction}

Severe acute respiratory syndrome (SARS) first emerged in southern China in the fall of 2002. Since then this infec- tious disease has become a global concern $[1,2,3]$. A novel coronavirus has been implicated with both the initial outbreak and the subsequent worldwide spread $[4,5,6]$. Cluster infections have been a common feature of SARS 
since its emergence $[1,2,3]$. In these clustered outbreaks some patients have progressed to respiratory failure while others have not deteriorated so markedly. The question of whether there are underlying factors that predispose to the eventual use of mechanical ventilation is important to address. In one study on 75 SARS patients the risk factors associated with acute respiratory distress syndrome requiring ventilatory support were age, male sex, chronic hepatitis B virus carriage, raised creatinine, and recurrent fever [7]. Fowler et al. [8] reported 38 patients with SARSrelated critical illness. They described clinical course and outcomes of these critical ill patients. They also found that older age, a history of diabetes mellitus, admission tachycardia, and elevated creatine kinase were associated with poor outcome.

We report here on a cluster of 44 SARS cases in a hospital chest ward in southern Taiwan. Analysis of clinical symptoms and laboratory data was undertaken with the aim of revealing risk factors for intubation in SARS patients. We focus on previous health SARS patients.

\section{Patients and methods}

Between 29 April and 26 May 2003 we identified 44 epidemiologically linked patients were identified in Chang Gang Memorial Hospital (29 women, 15 men; aged 22-82 years) 14 current inpatients, 14 familial relatives of these inpatients, and 16 health-care worker employed at the hospital. Of the 44 patients $20(45 \%)$ deteriorated to the point that intubation and mechanical ventilator support were required: 2 of the 16 health-care workers (13\%), 7 of 14 family members (50\%), and 11 of 14 inpatients (79\%). Of the 44 patients 18 died despite of ventilator support, and 26 are still alive. All these patients' serum tested for coronavirus IgG antibody were positive.

Patients' symptoms met the modified World Health Organization definition of SARS [6]. These are: a fever of $38^{\circ} \mathrm{C}$ or higher, cough or shortness of breath, and new pulmonary infiltrates on chest radiography that present in the absence of an alternative diagnosis to explain the clinical presentation. Respiratory secretions of all patients were analyzed for conventional bacteria, Legionella pneumophila, and mycobacteria. Serum samples were tested for Mycoplasma pneumoniae and Chlamydia pneumoniae. Serum samples in patients who are alive were tested for SARS coronavirus IgG antibody 1 month after discharge.

Data were collected retrospectively during SARS. The indi-


$\mathrm{FIO}_{2}$ ratio less than $300 \mathrm{mmHg}$ with $\mathrm{PaCO}_{2}$ greater than $50 \mathrm{mmHg}$ or a blood $\mathrm{pH}$ less than 7.25. The above committee consisting of three pulmonologists, two radiologists, and one infectious disease specialist reviewed each patient's charts and recorded demographic, clinical, and laboratory information on a standardized data collection form, and subsequently scrutinized the data to unearth risk factors for mechanical ventilation.

Student's $t$ test and Fisher's exact test were used in the univariate analysis, and multiple logistic regression was employed in the multivariate analysis. Differences with a $p$ value of 0.05 or less were considered significant.

\section{Results}

Table 1 displays the results of associated risk factors of the SARS patients based on the need for intubation. Patients who were intubated had a statistically significantly older age, underlying malignancy $(p=0.035)$, elevated initial white blood cell (WBC) count $(p<0.001)$, and higher C-reactive protein (CRP; $p=0.003$ ) compared to the patients who remained nonintubated. The predictive factors of intubation differed when the inpatient group was excluded from the statistical analysis (Table 2); those requiring intubation because of respiratory failure displayed higher age $(p=0.001)$, peak fever grade $(p=0.043)$, initial WBC count $(p<0.001)$, neutrophil count $(p<0.001)$, and neutrophil percentage $(p=0.002)$. Increased neutrophil count was the only significant variable in the multivariate analysis.

Of the 16 health-care workers 3 had participated in intubation procedures, 2 of whom subsequently deteriorated to respiratory failure. None of the 13 patients who had not participated in intubation procedures experienced respiratory failure. Among the 14 family members of inpatients 8 had maintained a bedside vigil while the visits of the other 6 were more sporadic. Of the 8 who maintained close and lengthy contact with an inpatient, 7 progressed to respiratory failure, while none of the 6 who had more sporadic contact with an inpatient experienced respiratory failure. Patients who were close or prolonged

Table 1 Associated risk factors of requirement for intubation in patients with SARS

\begin{tabular}{lccc}
\hline & $\begin{array}{l}\text { Intubation } \\
(n=20)\end{array}$ & $\begin{array}{l}\text { No intubation } \\
(n=24)\end{array}$ & $p$ \\
\hline Age (years) & $57.8 \pm 16.0$ & $35.9 \pm 14.4$ & $<0.001^{\mathrm{a} *}$ \\
Sex: F/M & $12 / 8$ & $17 / 7$ & $0.532^{\mathrm{b}}$ \\
Cardiac disease & $5(25 \%)$ & $3(12.5 \%)$ & $0.436^{\mathrm{b}}$ \\
Lung disease & $7(35 \%)$ & $2(8.3 \%)$ & $0.057^{\mathrm{b}}$ \\
Diabetes mellitus & $2(10 \%)$ & $2(8.3 \%)$ & $1.000^{\mathrm{b}}$ \\
Malignancy & $6(30 \%)$ & $1(4.2 \%)$ & $0.035^{\mathrm{b}}$ \\
White blood cells & $13,600 \pm 6,800$ & $5,400 \pm 3,000$ & $<0.001^{\mathrm{a}}$ \\
(per $\mu \mathrm{l})$ & & & \\
Neutrophils & $12,700 \pm 6,700$ & $4,400 \pm 2,900$ & $<0.001^{\mathrm{a}}$ \\
C-reacitve protein & $107.6 \pm 80.9$ & $38.2 \pm 50.4$ & $0.003^{\mathrm{a}}$ \\
\hline
\end{tabular}

${ }^{\text {a }}$ Student $t$ test

b Fisher's exact test

Table 2 Associated risk factors in previous healthy SARS patients who required intubation

\begin{tabular}{lccr}
\hline & $\begin{array}{l}\text { Intubation } \\
(n=9)\end{array}$ & $\begin{array}{l}\text { No intubation } \\
(n=21)\end{array}$ & \multicolumn{1}{c}{$p^{\mathrm{a}}$} \\
\hline Age (years) & $46.6 \pm 13.7$ & $31.8 \pm 8.6$ & 0.001 \\
Fever, peak $\left({ }^{\circ} \mathrm{C}\right)$ & $39.4 \pm 0.8$ & $38.6 \pm 0.9$ & 0.043 \\
WBC & $12,700 \pm 5,900$ & $5,000 \pm 2,800$ & $<0.001$ \\
Neutrophil & $11,800 \pm 5,900$ & $3,900 \pm 2,500$ & $<0.001$ \\
Neutrophil $(\%)$ & $91.9 \pm 4.3$ & $76.3 \pm 13.4$ & 0.002 \\
\hline a Student's $t$ test & & &
\end{tabular}


contact with a SARS patient had increased risk of respiratory failure $(p<0.001)$.

\section{Discussion}

The present report of a clustered SARS outbreak in Chang Gung Memorial Hospital, Kaohsiung, Taiwan, documents a rapid and widespread infection, particularly in the hospital's chest ward. A factor in the spread of the disease may have been the delay in diagnosis of the index case. This relates to the timing of the outbreak. At the time of the outbreak physicians generally lacked experience with SARS.

All 13 inpatients presented an abnormal chest radiography before their SARS diagnosis. In several patients there was little change in chest radiography findings, even when their lung function had deteriorated to the extent that intubation was necessary. It was thus more difficult to make the diagnosis of SARS in these patients. Physicians must pay more attention and keep alert for early diagnosis of SARS in inpatient group. Our observations serve as a cautionary note to physicians that increased attention might well be paid to inpatients if SARS is to be recognized early. Early detection of the infection and rapid isolation of SARS patient as well as intensive respiratory precautions are proving to be critical in the control of a more widely disseminated infection.

In the present cluster of patients a number of factors including age, underlying malignancy, WBC count, lymphocyte percentage, and CRP level differ significantly in patients who required intubation from those who did not require intubation. The physiological factors were likely associated with underlying malignancy, which was significantly greater in the intubated patients. Diseases such as chronic obstructive pulmonary disease and lung cancer are more prevalent in older persons and are usually associated with secondary infections that influence WBC count, neutrophil count, lymphocyte percentage, and CRP level. As a result the use of physiological parameters may not be a reliable prognosticator of impending respiratory failure in some SARS patients.

The above statement is not absolute. Indeed, in SARS patients who were healthy prior to developing this in- fection, factors such as age, peak fever grade, WBC count, and neutrophil percentage may prove to be reliable risk factors for the progression to intubation. The elderly have a higher risk of respiratory failure. Moreover, a highgrade fever grade $\left(>39.4^{\circ} \mathrm{C}\right)$ may indicate a severe inflammation or a cytokine storm. Older patients suffering from SARS who develop a high fever may thus be at greater risk of intubation.

Two of the three health-care workers who had participated in intubation procedures on SARS patients progressed to acute respiratory failure. In contrast, the 13 health-care workers who had not assisted in the intubation of SARS patients did not experience respiratory failure when they subsequently contracted SARS. Furthermore, of the eight family members of inpatients who kept a bedside vigil, seven progressed to acute respiratory failure. However, family members who visited an inpatient more sporadically did not succumb to respiratory failure when they contracted SARS. These observations are consistent with the suggestion that close contact with SARS patients increases the risk of respiratory failure and intubation. In our hospital 20 of $44(36 \%)$ SARS patients progressed to acute respiratory failure, including nine of $30(30 \%)$ previously healthy persons and 11 of $14(79 \%)$ inpatients.

This incidence of acute respiratory failure is higher than noted at other hospital $[7,8,9,10,11,12,13]$. Some of the original inpatients had underlying lung disease including chronic obstructive pulmonary disease, asthma, and lung cancer. It is reasonable to presume that respiratory failure rate would be greater in this patient group given these other physiological stresses. However, possibly muting the influence of these others clinical stresses are the findings that in other SARS outbreaks, previously healthy patients displayed an acute respiratory rate of $36 \%[7,8,9,10,11,12,13]$. Thus, whether a person's current health status affects their susceptibility to acquire SARS is uncertain and requires further study.

In conclusion, the current study provide evidence that older age, high WBC counts, high peak grade fever, and close or prolonged contact with a SARS patient can be risk factors in the respiratory deterioration of previous healthy SARS patients leading to intubation and mechanical ventilator support.

\section{References}

1. Tsang KW, Ho PL, Ooi GC, Yee WK, Wang T, Yeung MC, Lam WK, Seto WH, Yam LY, Cheung TM, Wong PC, Lam B, Ip MS, Chan J, Yuen KY, Lai KN (2003) A cluster of cases of severe acute respiratory syndrome in Hong Kong. New Engl J Med 348:1977-1985
2. Booth CM, Matukas LM, Tomlinson GA, Rachlis AR, Rose DB, Dwosh HA, Walmsley SL, Mazzulli T, Avendano M, Derkach P, Ephtimios IE, Kitai I, Mederski BD, Shadowitz SB, Gold WL, Hawryluck LA, Rea E, Chenkin JS, Cescon DW, Poutanen SM, Detsky AS (2003) Clinical features and short-term outcomes of 144 patients with SARS in the greater Toronto area. JAMA 289:2801-2809
3. Anonymous (2003) Update: outbreak of severe acute respiratory syndromeworldwide. MMWR Morb Mortal Wkly Rep 52:269-273 
4. Ksiazek GG, Erdman D, Goldsmith CS, Zaki SR, Peret T, Eermy S, Tong S, Urbani C, Comer JA, Lim W, Rollin PE, Dowell SF, Ling AE, Humphrey $\mathrm{CD}$, Shieh WJ, Guarner J, Paddock CD, Rota P, Fields B, DeRisi J, Yang JY, Cox N, Hughes JM, LeDuc JW, Bellini WJ, Anderson LJ (2003) A novel coronavirus associated with severe acute respiratory syndrome. New Engl J Med 348:1953-1966

5. Holmes KV (2003) SARS coronavirus: a new challenge for prevention and therapy. J Clin Invest 111:1605-1609

6. Peiris JS, Lai ST, Poon LL, Guan Y, Yam LY, Nicholls WL, Yee WK, Yan WW, Cheung MT, Cheng VC, Chan KH, Tsang DN, Yung RW, NG TK, Yuen KY (2003) Coronavirus as a possible cause of severe acute respiratory syndrome. Lancet 361:1319-1325
7. Peiris Js, Chu CM, Cheng VC, Hung IF, Poon LL, Law KI, Tang BS, Hon TY, Chan CS, Chan KH, Ng JS, Zheng BJ, $\mathrm{Ng}$ WL, Lai RW, Guan Y, Yuen KY (2003) Clinical progression and viral load in a community outbreak of coronavirus-associated SARS pneumonia: a prospective study. Lancet 361:17671772

8. Fowler RA, Lapinsky SE, Hallett D, Destky AS, Sibbald WJ, Slutsky AS, Stewart TE (2003) Critically ill patients with severe acute respiratory syndrome. JAMA 290:367-373
9. Lew TW, Kwek TK, Tai D, Earnest A, Loo S, Singh K, Kwan KM, Chan Y, Yim CF, Bek SL, Kor AC, Yap WS, Chelliah YR, Lai YC, Goh SK (2003) Acute respiratory distress syndrome in critically ill patients with severe acute respiratory syndrome. JAMA 290:374380

10. Masur H, Emanuel E, Lane HC (2003) Severe acute respiratory syndrome. JAMA 289:2861-2863

11. Anonymous (2003) Severe acute respiratory syndrome-Singapore. MMWR Morb Mortal Wkly Rep 52:405-411

12. Anonymous (2003) Severe acute respiratory syndrome-Taiwan. MMWR Morb Mortal Wkly Rep 52:461-466

13. Anonymous (2003) Preliminary clinical description of severe acute respiratory syndrome. MMWR Morb Mortal Wkly Rep 52:255-256 